\title{
ELECTROCHEMICAL OXIDATION OF 10H-PHENOTHIAZINE-1-CARBOXYLIC ACID
}

\author{
ANA-MARIA SĂCARĂ ${ }^{a}$, CASTELIA CRISTEA $^{a}$, TAMAS LOVASZ $^{a}$, \\ DAN PORUMB ${ }^{a}$, EVA MOLNAR ${ }^{a}$ and LIANA MARIA MURESAN ${ }^{a}$
}

\begin{abstract}
The electrochemical behavior of $10 \mathrm{H}$-phenothiazine-1-carboxylic acid was investigated by square wave anodic stripping voltammetry (SWASV) at a glassy carbon electrode, which evidenced the first monoelectronic oxidation step at low potentials (around $0.25 \mathrm{~V}$ ), slightly modulated by the nature of the solvent. The effect of three different solvents (acetonitrile, dimethyl sulfoxide and chloroform) on the strength of intramolecular hydrogen bonding associations was evidenced by DFT calculations. The computed electron density at the heterocyclic nitrogen atom appeared well correlated to the recorded oxidation potential. The possibility to use of $10 \mathrm{H}$-phenothiazine-1-carboxylic acid as potential mediator for electrochemical detection of Malachite Green was explored, but the phenothiazine derivative appeared not suitable for the detection of the dye.
\end{abstract}

Keywords: 10H-phenothiazine-1-carboxylic acid, SWASV, intramolecular hydrogen bonds

\section{INTRODUCTION}

A significant characteristic of phenothiazine derivatives appeared to be their ability to readily generate various oxidation products under chemical, photochemical, enzymatic, or electrochemical conditions. The redox properties of several phenothiazine derivatives with important medicinal applications were largely exploited in analytical procedures tailored for the advanced detection of phenothiazine based neuroleptic drugs $[1,2]$. The electrochemical oxidation of phenothiazine and its derivatives proceeds on conventional

\footnotetext{
a Babeş-Bolyai University, Faculty of Chemistry and Chemical Engineering, 11 Arany Janos str., RO-400028, Cluj-Napoca, Romania

*Corresponding author: limur@chem.ubbcluj.ro
} 
electrodes ( $\mathrm{Pt}$, glassy carbon electrode and $\mathrm{Au}$ ) either in organic or in aqueous acidic medium. The oxidation of the phenothiazine core takes place by the intermediate stage of radical cation with a stability influenced by the nature and position of the substituents on the heterocyclic core, the acidity and the presence of various salts in the reaction medium. Further oxidation steps imply the formation of the phenothiazinium cation which usually generates a colorless phenothiazine sulfoxide, colored hydroxy-substituted or polymeric derivatives [3]. Based on the reversibility of its first monoelectronic redox process, phenothiazine was described to be an efficient mediator in various electrochemical oxidation processes. For instance, it displayed excellent electrochemical catalytic activities for oxidase enzymes (glucose, lactate and cholesterol oxidase) even when immobilised on the surface of the electrode $[4,5]$ and enzyme glucose dehydrogenase [6]. Several phenothiazine derivatives, were studied as electron transfer mediators in different electrochemical systems $[7,8]$. On the other hand, a series of 1-carboxyphenothiazine derivatives was synthesized and characterized [9], but there are no reported evidences for their utility as mediators for electrochemical systems.

Considering our previous interest in the electrochemical detection of Malachite Green (MG) [10], the aim of this work was to explore the electrochemical reactivity of $10 \mathrm{H}$-phenothiazine-1-carboxylic acid and its potential as mediator for the electrochemical detection of the dye. Based on the electrostatic attraction between a carboxy functionality attached to the phenothiazine core and the positively charged MG cationic dye, it was expected that the diffusion/adsorption of the dye to a carboxyphenothiazine modified electrode surface would be facilitated.

\section{RESULTS AND DISCUSSION}

$10 H$-Phenothiazine-1-carboxylic acid 1 was synthesized by optimizing a previously reported synthetic protocol [9] based on the thiation of N-phenyl-antranilic acid (scheme 1).<smiles>O=C(O)c1ccccc1Nc1ccccc1</smiles>

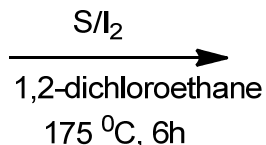<smiles>O=C(O)c1cccc2c1Nc1ccccc1S2</smiles>

\section{Scheme 1}


The structure of 1 was confirmed by spectroscopic methods. ${ }^{1} \mathrm{H}-\mathrm{NMR}$ spectrum of 1 displayed a deshielded signal characteristic to the acidic proton situated at $10.15 \mathrm{ppm}$, accompanied by the signals of aromatic protons situated in the region 6.7-7.6 ppm.

The position of the carboxyl group in the neighborhood of the heterocyclic $\mathrm{NH}$ group favors the formation of intramolecular hydrogen bonds. Density functional theory (DFT) calculations were applied to emphasize the possible intramolecular hydrogen bond formation. Thus, the structure of 1 was initially optimized using Spartan 06 with DFT B3LYP 6-31 $\mathrm{G}^{*}$ method in gas phase. Free rotation of the carboxyl substituent generated two conformers of 1 with computed minimal energy which are presented in Figure 1. Conformer $1 \mathrm{a}$ is characterized by hydrogen bond interaction between heterocyclic $\mathrm{NH}$ and carboxyl substituent, while conformer $\mathbf{1 b}$ does not contain a hydrogen bond.

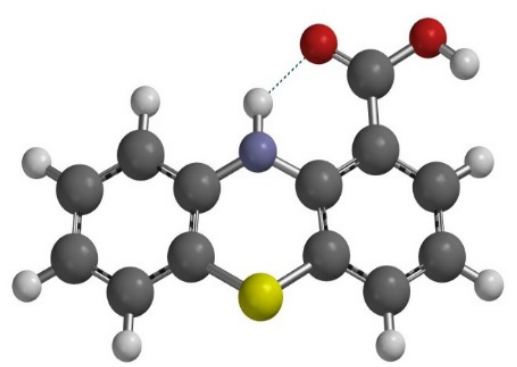

1a

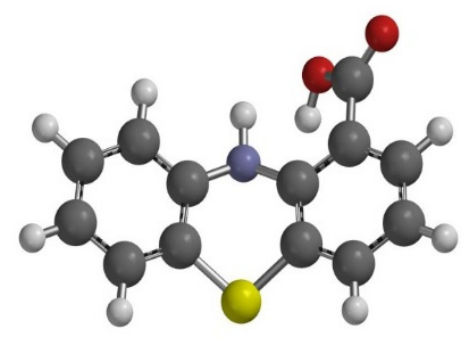

$1 b$

Figure 1. Conformers of $10 \mathrm{H}$-phenothiazine-1-carboxylic acid 1 with optimized geometry

Due to the fact that solvents may influence the hydrogen bonding [11], conformer $1 \mathrm{a}$ has been optimized by B3LYP/6-31++G(d,p) Gaussian method using three data sets for the following solvents: acetonitrile, chloroform and DMSO. The results are illustrated in Table 1.

As it may be seen from table 1, 1a appears to be more stable than 1b (molecular energy difference $5.25 \mathrm{kcal} / \mathrm{mole}$ in gas phase) and the interactions with the aprotic dipolar solvents suggested further stabilization effects upon $1 \mathrm{a}$.

Square wave anodic stripping voltammetry experiments were performed in order to explore the electrochemical reactivity of $10 \mathrm{H}$-phenothiazine-1carboxylic acid dissolved in three different solvents and deposited on the surface of a glassy carbon electrode. The voltammograms presented in Figure 2 are showing well defined oxidation peaks corresponding to phenothiazine radical cationic species. 
Table 1. Gaussian B3LYP/6-31++G(d,p) computational results for $10 \mathrm{H}-$ phenothiazine-1-carboxylic acid: optimized geometry, molecular energy $(E)$ and electrostatic charge on heterocyclic nitrogen atom in gas phase and different solvents

\begin{tabular}{|c|l|c|c|}
\hline Conformer & Environment & $\begin{array}{c}\mathrm{E} \\
(\mathrm{kcal} / \mathrm{mol})\end{array}$ & $\begin{array}{c}\text { Electrostatic charge } \\
\text { on N atom }\end{array}$ \\
\hline \multirow{2}{*}{ 1b } & Vacuum & -692898.748 & -0.709 \\
\hline \multirow{6}{*}{ a } & Vacuum & -692904.000 & -0.630 \\
\cline { 2 - 4 } & Acetonitrile & -693049.921 & 0.126 \\
\cline { 2 - 4 } & Chloroform & -693047.637 & 0.132 \\
\cline { 2 - 4 } & DMSO & -693050.015 & 0.125 \\
\hline
\end{tabular}

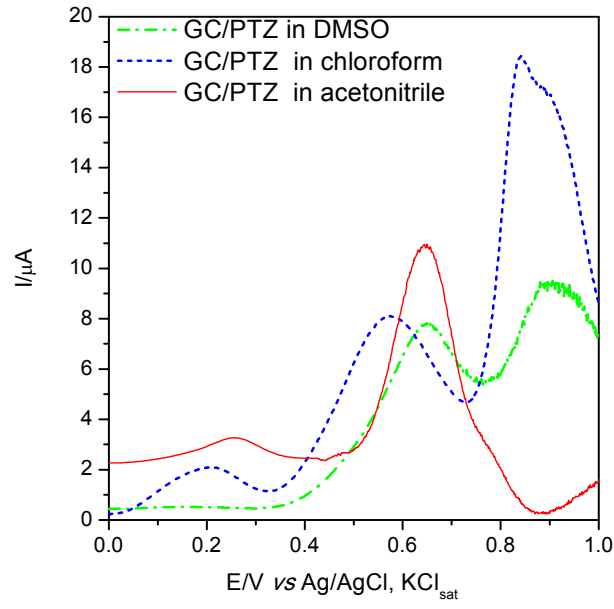

a

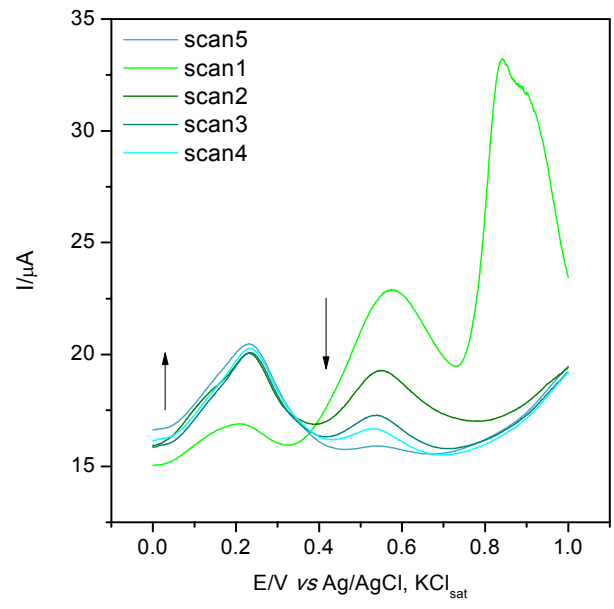

b

Figure 2. SWASV at glassy carbon (GC) electrodes modified with $10 \mathrm{H}$-phenothiazine-1-carboxylic acid (PTZ) a) in different solvents; b) several scans in acetonitrile. Experimental conditions: $\mathrm{pH}=3$, accumulation time $300 \mathrm{~s}$; frequency $25 \mathrm{~Hz}$; potential oxidation processes interval 0-1 V.

In scheme 2 are described the oxidation steps proposed in order to assign the SWASV peaks observed in figure 2. The first monoelectronic oxidation step generates the radical cation 2 and the values of the typical potentials may be correlated to the computational results related to electron density at the heterocyclic nitrogen atom presented in table 1 . The lowest oxidation potential $(0.25 \mathrm{~V})$ may be assigned to $1 \mathrm{a}$ characterized by higher electron density as compared to $\mathbf{1 b}$, which in turn may be responsible for the oxidation peak situated at $0.55 \mathrm{~V}$. Further step requires a higher oxidation potential and generates the cation 3 which may end up as a colourless sulfoxide 4 . As it may be seen in figure 
$2 \mathrm{~b}$, after several scans the intensity of the first oxidation peak increases (maybe due to the reversibility of the oxidation processes of $\mathbf{1 a}$ ), while the oxidation of $\mathbf{1 b}$ proceeding towards the chemical reaction may explain the consumption of the radical cationic species $\mathbf{2} \mathbf{b}$ and consequently the decrease in intensity of the second oxidation peak.

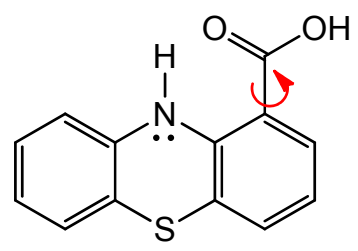

1b

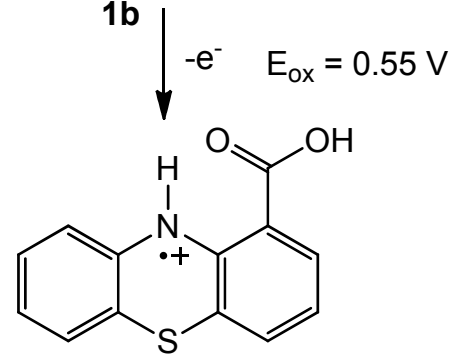

2b

-e $^{-} \quad E_{o x}=0.85 \mathrm{~V}$<smiles>O=C(O)c1cccc2c1Nc1ccccc1S2</smiles>

3<smiles></smiles>

$1 \mathrm{a}$<smiles>O=C1O[In]2c3ccccc3Sc3cccc1c32</smiles>

$2 a$<smiles>O=C(O)c1cccc2c1Nc1ccccc1S2</smiles>

4

\section{Scheme 2}

A characteristic signal of the sulfoxide was recorded by ${ }^{1} \mathrm{H}-\mathrm{NMR}$ (in deuterated acetonitrile solution) at chemical shift $11.65 \mathrm{ppm}$.

The SWASV experiments performed in the presence of MG indicated a decrease in intensity of the first oxidation peak (figure 3a), which may be correlated to steric interactions between 1 and the bulky cationic dye in control for weakening the intramolecular hydrogen bond associations. Calibration curves presented in figure $3 \mathrm{~b}$ indicate a feeble correlation with the MG concentration and do not sustain the possibility of elaborating an analytical procedure for MG detection. 


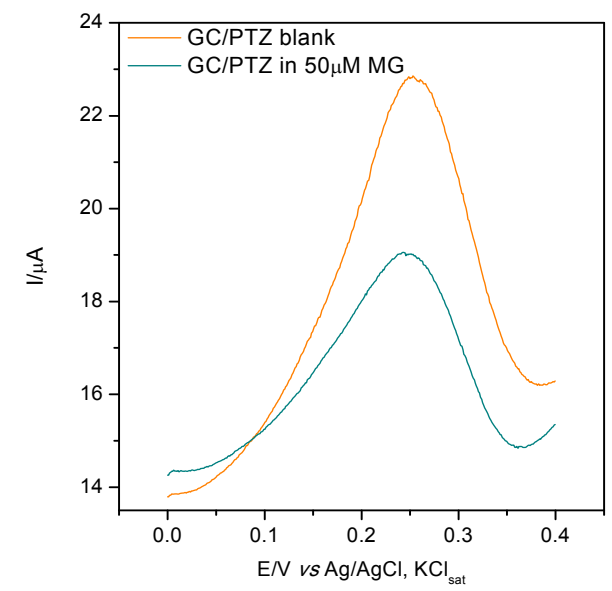

a

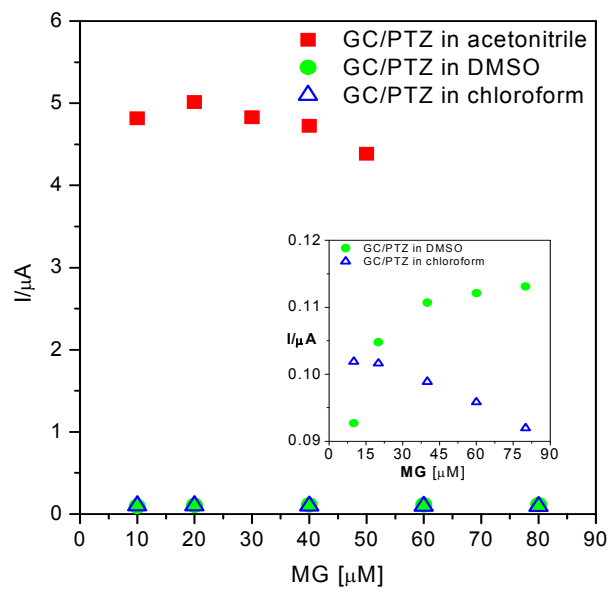

b

Figure 3. SWASV at GC/10H-phenothiazine-1-carboxylic acid (PTZ) electrodes: a) in the presence of malachite green (MG). b) Calibration curves obtained for increasing amounts of MG. Experimental conditions: accumulation time $300 \mathrm{~s}$; frequency $25 \mathrm{~Hz}$; potential interval 0-0.4 V; electrolyte phosphate buffer $(\mathrm{pH} 3)$.

\section{CONCLUSIONS}

The oxidation potential of $10 \mathrm{H}$-phenothiazine-carboxilic acid appeared to be lowered by intramolecular hydrogen bond associations. The first monoelectronic oxidation step generating the radical cation occurred around $0.25 \mathrm{~V}$, this value being slightly modulated by the nature of the solvent.

No favourable interactions between $\mathrm{MG}$ and $10 \mathrm{H}$-phenothiazine-carboxilic acid occurred and, consequently the tested electrochemical system based on $\mathrm{GC} / 10 H$-phenothiazin-carboxilic acid is not suitable for the detection of MG.

\section{EXPERIMENTAL SECTION}

\section{Chemicals}

All the chemicals used for the experiments in this study were of analytical grade quality and were used as received, without further purification or alteration.

Malachite Green oxalate salt was purchased from Penta, Czech Republic and all solutions were made in $\mathrm{pH} 3$ phosphate buffer (PB). Phosphate buffer solution was made starting from $\mathrm{NaH}_{2} \mathrm{PO}_{4}{ }^{*} \mathrm{H}_{2} \mathrm{O}$ and $\mathrm{Na}_{2} \mathrm{HPO}_{4}$ salts and $\mathrm{pH}$ adjusted with $\mathrm{o}-\mathrm{H}_{3} \mathrm{PO}_{4}$ acid, all from Merck, Germany. 


\section{H-Phenothiazine-1-carboxylic acid 1 preparation}

$\mathrm{N}$-phenylanthranilic acid $6.4 \mathrm{~g}$ (0.03 mole), sulfur powder $1.92 \mathrm{~g} \mathrm{(0.06}$ mole) and iodine $0.8 \mathrm{~g}$ ( 0.006 mole) were dissolved in $60 \mathrm{ml}$ 1,2-dichlorobenzene. The reaction mixture was heated at $175^{\circ} \mathrm{C}$ for $6 \mathrm{~h}$ under constant stirring. After cooling at room temperature, $10 \mathrm{ml}$ solution of sodium thiosulphate $40 \%$ was added to the reaction mixture. The organic layer was separated and the organic solvent was removed by vacuum distillation. The product was purified by column chromatography on silica gel using eluent toluene to give orange coloured $10 \mathrm{H}$ phenothiazine-1-carboxylic acid (1.4 g, yield 19\%). M.p. $248{ }^{\circ} \mathrm{C}$ (lit. [9])

${ }^{1} \mathrm{H}$ NMR(DMSO-d 6 , 400 MHz, ppm): 6,88-7,04 (m, 5H, Ar-H), 7,18 (d, 1H, Ar-H), $7,65(\mathrm{~d}, 1 \mathrm{H}, \mathrm{Ar}-\mathrm{H}), 9,63(\mathrm{~s}, 1 \mathrm{H},-\mathrm{N}-\mathrm{H}), 10,15(\mathrm{~s}, 1 \mathrm{H},-\mathrm{COOH})$

\section{Electrode preparation}

Before conducting any measurements, the glassy carbon (GC) working electrode was thoroughly cleaned on a piece of felt with $\mathrm{y}$-alumina slurry until mirror-like shine aspect was obtained. In order to remove any traces of impurities, further cleaning was applied by sonication in acetone and distilled water respectively.

For modifying the electrode, saturated $10 \mathrm{H}$-phenothiazine-1-carboxylic acid solutions were prepared, in three different solvents: chloroform, acetonitrile and dimethyl-sulfoxide. Each solution was applied by drop-casting on the electrode's active surface and allowed to dry freely. In the case of DMSO solutions, a warm air current was applied to accelerate the evaporation process. Constant $5 \mu \mathrm{L}$ volumes of solutions were employed for all electrode modification purposes. No other protective coatings were applied on the modified electrode as the evaporated phenothiazine carboxylic acid layer had a good stability during measurements in aqueous solutions.

\section{Electrochemical measurements}

All electrochemical experiments were performed on a Metrohm Autolab PGSTAT 302N, electrochemical workstation (Eco Chemie, Netherlands). A three-electrode system composed of a $\mathrm{Ag} / \mathrm{AgCl}, \mathrm{KCl}$ sat reference electrode, a platinum counter-electrode and a bare or modified glassy carbon (GC) working electrode was used. The electrolyte solution contained $0.1 \mathrm{M}$ phosphate buffer adjusted with o- $\mathrm{H}_{3} \mathrm{PO}_{4}$ at $\mathrm{pH} 3$. All experiments were performed at a room temperature of $25^{\circ} \mathrm{C}$. 


\section{REFERENCES}

1. K. Madej, P. Koscielniak, Critical Reviews in Analytical Chemistry, 2008, 38 50.

2. K. Nesměrák V. Červený, J. Hraníček, P. Rychlovský, Microchemical Journal, 2013, 106. 226.

3. H. Puzanowska-Tarasiewicz, L. Kuzmicka, J. Karpinska, K. Mielech-Lucasiewicz, Analytical Sciences, 2005, 21, 1149.

4. A.N. Sekretaryova, M.Yu. Vagin, V. Beni, A.P.F. Turner, A.A. Karyakin, Biosensors and Bioelectronics, 2014, 53, 275;

5. J. Kulysa, T. Buch-Rasmussenb, K. Bechgaard, V. Razumasa, Journal of Molecular Catalysts, 1994, 91, 407.

6. T Hoshino, S. Sekiguchi, H. Muguruma, Bioelectrochemistry, 2012, 84, 1.

7. B. Brunetti, P. Ugo, L.M. Moretto, C.R. Martin, Journal of Electroanalytical Chemistry, 2000, 491, 166.

8. H. Dai, H. Xu, X. Wu, Y. Lin, M. Wei, G. Chen, Talanta, 2010, 81, 1461.

9. V.B. Kataria, M.J. Solanki, A.R. Trivedi, V.H. Shah, Letters in Drug Design \& Discovery, 2013, 10(10), 951.

10. A. Sacara, C. Cristea, L.M. Muresan, Journal of Electroanalytical Chemistry, 2017, 792, 23.

11. J.L. Cook, C.A. Hunter, C.M.R. Low, A. Perez-Velasco, J.G. Vinter. Angewandte Chemie International Ed., 2007, 46, 3706. 